\title{
A UTILIZAÇÃO DE DADOS GEOLÓGICOS E GEOMORFOLÓGICOS NA IDENTIFICAÇÃO DE ÁREAS SUSCETÍVEIS A DESASTRES NATURAIS. ESTUDO DE CASO: BACIA HIDRO- GRÁGICA DO RIO PARANHANA/RS
}

\author{
Andrea Cristina Conceição Lemos ${ }^{1}$ \\ ${ }^{1}$ Universidade Federal do Rio Grande do Sul. E-mail: andrealemos.geo@gmail.com. \\ Recebido em 07/2013. Aceito para publicação em 10/2013. \\ Versão online publicada em 19/09/2014 (http://seer.ufrgs.br/paraonde)
}

\begin{abstract}
Resumo: 0 processo de reconhecimento geológico-geomorfológico tem como rotina fundamental a divisão da área em unidades, de acordo com suas características. Essas unidades representam as heterogeneidades, mínima quanto aos atributos e, em compartimentos com semelhanças frente aos processos da dinâmica superficial. Por apresentarem um relevo escarpado, as regiões de encosta do planalto no Rio Grande do Sul são palco de frequentes desastres naturais, como os movimentos de massa. Qualquer alteração nos componentes da natureza (relevo, solo, vegetação, clima e recursos hídricos) acarreta no comprometimento da funcionalidade do sistema, rompendo desta forma com o equilíbrio dinâmico existente. Na Bacia Hidrográfica do Rio Paranhana situada à margem direita do Rio dos Sinos, na encosta do Planalto Meridional, as inundações e os movimentos de massa são decorrentes do relevo caracteristicamente escarpado. Trabalhos desenvolvidos na área de estudo identificaram, junto à Defesa Civil, a ocorrência, entre os anos de 2003 a 2012, de trinta e sete ocorrências de desastres naturais caracterizados como: vendaval, tornado, enchente, inundação, alagamento, movimentos de massa e granizo. Neste contexto, os estudos geológico-geomorfológicos são importantes para auxiliar no planejamento e mapeamento de áreas de fragilidade ambiental. A interpretação dos dados, geológicos e geomorfológico somado aos dados de campo possibilitou pontuar zonas mais susceptíveis. Estas zonas se registram principalmente nos municípios de Três Coroas e Igrejinha, onde o substrato é caracterizado por arenitos da Formação Botucatu e zonas de contato com basaltos da Formação Serra Geral.

Palavras Chave: Bacia Hidrográfica do Rio Paranhana; Geologia; Geomorfologia; Susceptibilidade Ambiental.
\end{abstract}

\section{Introdução}

O estudo geomorfológico de cunho geográfico e geológico apresenta um estreito vínculo com a análise do ambiente. Pode-se dizer que a geomorfologia privilegia os estudos morfogenéticos e a busca da gênese das formas. Já, a geomorfologia de cunho geológico privilegia a configuração espacial da arquitetura do embasamento rochoso.

Este processo de reconhecimento geológico-geomorfológico tem como rotina a divisão da área em unidades, de acordo com a variação de suas características (padrões de formas semelhantes e padrões de formas de relevo). As unidades representam áreas com heterogeneidade mínima quanto aos atributos e, em compartimentos com respostas semelhantes frente aos processos de dinâmica superficial.

A pesquisa geomorfológica procura entender as feições do terreno tornando compreensíveis os processos que atuam na superfície. Essa meta, por si só, dá ideia da complexidade dos processos e fenômenos envolvidos. Reconhecer as diferentes litologias é importante, visto que diferentes rochas apresentam comportamentos diferenciados frente aos processos de intemperismo originando variados materiais de cober- tura e a ocorrência de processos erosivos, movimentos de massa e inundação (FUJIMOTO, 2001).

Devido ao relevo escarpado, as regiões da encosta do planalto são palco de frequentes desastres naturais (movimentos de massa e inundações). Segundo Ross (1994) qualquer alteração nos componentes da natureza (relevo, solo, vegetação, clima e recursos hídricos) acarreta no comprometimento da funcionalidade do sistema, rompendo desta forma com o equilíbrio dinâmico.

A Bacia Hidrográfica do Rio dos Sinos (BHRS) situada no nordeste do estado do Rio Grande do Sul abrange municípios como Novo Hamburgo, Parobé e Taquara pertencente à Região Metropolitana de Porto Alegre (RMPA) os quais são densamente povoados. De acordo com estudos realizados por grupos de pesquisas da Universidade Federal do Rio Grande do Sul (UFRGS), cujo tema é a análise da Bacia Hidrográfica do Rio Sinos - RS, com ênfase nas áreas suscetíveis a inundações e a movimentos de massa e modelagem atmosférica, o principal problema ambiental desta região está vinculado a inundações de variável magnitude (OLIVEIRA, 2010).

Na Bacia Hidrográfica do Rio Paranhana (BHRP), situada à margem direita do Rio dos Sinos, unidade geomorfológica do Planalto Meridional (IBGE, 2003), 
somam-se às inundações, os movimentos de massa das encostas, decorrentes do relevo escarpado. Conforme diagnosticado por Riffel (2012), nesta área a Defesa Civil diagnosticou entre os anos de 2003 a 2012, trinta e sete ocorrências de desastres naturais caracterizados como: vendaval, tornado, enchente, inundação, alagamento, movimentos de massa e granizo.

Desta forma o presente trabalho tem como objetivo, relacionar as características geológicas e geomorfológicas da região da Bacia Hidrográfica do Rio Paranhana, de modo a identificar zonas suscetíveis a desastres naturais. Estudos voltados à relação entre o substrato $\mathrm{e}$ as formas de relevo visando o planejamento ambiental vêm se tornando, nas últimas décadas, prioridade na identificação de áreas susceptíveis a desastres naturais como movimentos de massa, principalmente em regiões da encosta do planalto.

\section{Área de Estudo}

A hidrografia do estado do Rio Grande do Sul divide-se em três regiões: Guaíba, Litoral e Uruguai (PRÓ-SINOS, 2013). A região hidrográfica do Guaíba é composta por nove bacias: Vacacaí, Pardo, Baixo Jacuí, Alto Jacuí, Taquari-Antas, Caí, Sinos, Gravataí e Lago Guaíba. A bacia hidrográfica do Rio dos Sinos é a bacia mais estudada no estado tendo em vista a densidade demográ- fica e industrial que eleva a taxa de contaminação com produtos químicos gerados principalmente pelo setor coureiro calçadista (BASSO, 2004).

Com uma área de $3.596 \mathrm{~km}^{2}$ e com uma população de cerca de 1,5 milhões de habitantes, a Bacia Hidrográfica do Rio dos Sinos tem suas nascentes no município de Caraá, em altitude de aproximadamente 700 $\mathrm{m}$. Seus principais afluentes a margem direita são os rios - Rolante, da Ilha e Paranhana, sendo este último o objeto de estudo do presente trabalho.

o Rio Paranhana localiza-se em uma região de relevo fortemente ondulado e escarpado por situar-se na encosta do planalto. Esta bacia possui uma área de $572,22 \mathrm{~km}^{2}$ e está inserida na Bacia Hidrográfica do Rio dos Sinos no centro-nordeste do estado do Rio Grande do Sul (Figura 1) entre as coordenadas geográficas -

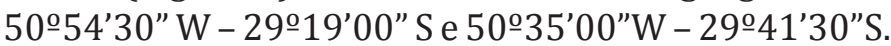

A rede hídrica do Rio Paranhana se forma a partir das águas transpostas da Bacia Hidrográfica do Rio Caí das barragens do Salto, Divisa e Blang. Possui suas nascentes localizadas nos municípios de Canela, Gramado e São Francisco de Paula, a cerca de 900 m de altitude e sua confluência com o rio dos Sinos localiza-se no município de Taquara a uma altitude de $20 \mathrm{~m}$ (Riffel, 2012). Os municípios que compõe a BHRP são: Parobé, Taquara, Igrejinha, Três Coroas, São Francisco de Paula, Gramado e Canela.

Figura. 1 - Localização da Bacia Hidrográfica do Rio Paranhana.

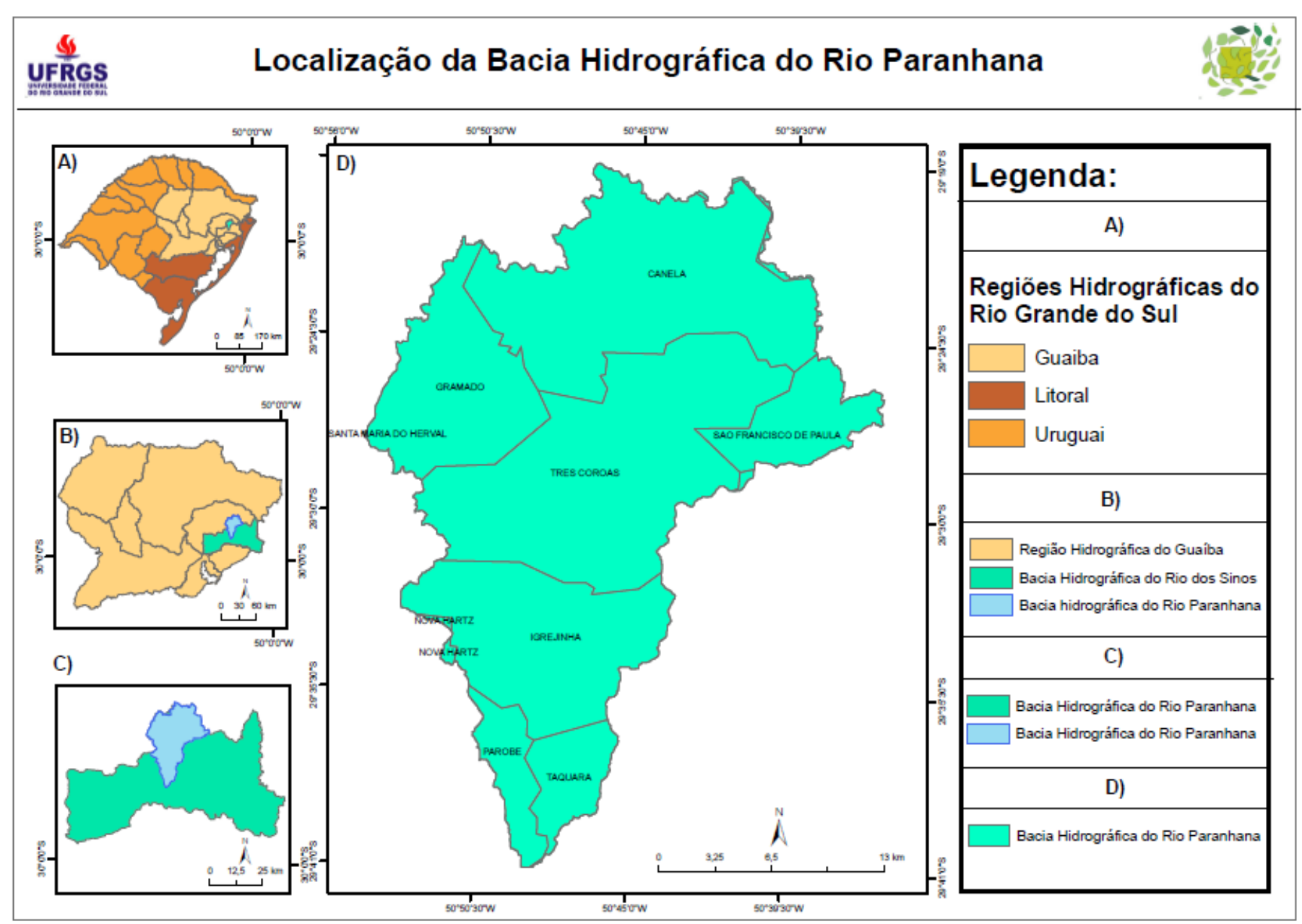




\section{Geologia}

A unidade geológica desta área corresponde à porção sudeste da Bacia do Paraná a qual se constitui como uma bacia intracratônica, desenvolvida sobre a crosta continental sendo preenchida por rochas sedimentares e vulcânicas (BORSATTO, 2011).

Nesta região estão presentes litologias correspondentes a supersequência Gondwana III (MILANI, 1997) da mais antiga para mais recente: Formação Botucatu e Formação Serra Geral. Esta última representa a área de estudo pelas Fácies Caxias e Gramado. As rochas da Fácies Caxias são de composição ácida apresentando-se mais resistentes devido ao alto teor de sílica em sua composição mineralógica. As mesmas são encontradas na borda norte da BHRP. As rochas da Fácies Gramado são de composição básica sendo representadas pelos basaltos que cobrem cerca de $80 \%$ da área da BHRP.

\section{Geomorfologia}

A Bacia Hidrográfica do Rio Paranhana situa-se na região geomorfológica do Planalto das Araucárias e na Depressão Central Gaúcha. Dividindo-se nas Unidades Geomorfológicas (UG) do Planalto dos Campos Gerais, Serra Geral, Patamares da Serra Geral e Planície Alúvio-Coluvionar e Depressão do Rio Jacuí (IBGE, 2000).

O relevo do Planalto dos Campos Gerais de acordo com o RADAM BRASIL (1986) foi desenvolvido sobre as formações vulcânicas sendo marcado por colinas de pequena amplitude, separadas por vales alargados por sucessivas etapas de dissecação que deixaram rupturas de declives e pequenos desníveis. Esta unidade geomorfológica (UG) caracteriza-se por apresentar morfologia planar e está situada em altimetrias superiores a 650 m e declividades inferiores a 25\% (LUERCE, 2013).

A UG Serra Geral está vinculada as regiões onde o substrato é composto por rochas vulcânicas básicas abrangendo todos os municípios da bacia do Rio Paranhana. Situa-se a Sul, logo abaixo (direção Norte-Sul) do Planalto dos Campos Gerais nos terminais escarpados e abruptos. Esta região é propícia para o desenvolvimento e preservação da vegetação florestal. Segundo Luerce (2013) as formas de relevo são bastante abruptas com vales encaixados bem aprofundados, nesta UG a altimetria varia entre 180 e $650 \mathrm{~m}$ e a declividade é maior de $25 \%$.

Nos terminais rebaixados da Serra Geral encontra-se a UG Patamares da Serra Geral. Nesta unidade o relevo de colinas apoia-se no substrato arenítico da Formação Botucatu. Os morros apresentam baixo aprofundamento dos vales fluviais. A altimetria varia entre 60 e $180 \mathrm{~m}$.

Nas áreas de altimetria inferior a 20 m encontra a UG, da planície Alúvio-Coluvionar que corresponde à superfície plana, resultante da convergência de leques de espraiamento e concentração de depósitos de enxurradas nas partes terminais de pedimentos (IBGE, 2000).
Localizada entre os domínios do Planalto das Araucárias e Planície Continental está a Depressão do Rio Jacuí que apresenta relevo sem grandes variações altimétricas com colinas de topos convexos ou coxilhas em sua maioria situada sobre a Formação Botucatu.

\section{Materiais e Métodos}

A caracterização geológica da bacia hidrográfica do Rio Paranhana foi realizada em seis etapas de trabalho. Na primeira etapa fez-se uma revisão bibliográfica acerca das rochas da Bacia do Paraná visando identificar e compreender as principais unidades geológicas que compõe a área de estudo.

Na segunda etapa de trabalho foram selecionados mapas geológicos ancestrais (Folha Gravataí-litologia, escala 1:250.000 - IBGE), cartas DSG de base (Taquara, Três Coroas, Gramado, Canela e São Francisco de Paula, escala 1:50.000). Para reconhecer as principais estruturas regionais e feições geomorfológicas, selecionou-se a Folha 29s51 dos dados SRTM/TOPODATA, para extrair as variáveis geomorfométricas.

Na terceira etapa foram realizadas três campanhas de obtenção de dados de campo, totalizando o cadastro de oitenta e quatro afloramentos descritos e distribuídos de modo aleatório pela BHRP. 0 trabalho de campo destinou-se inicialmente ao reconhecimento da área de estudo e à aferição dos dados obtidos nesta fase pré-campo, como por exemplo, o reconhecimento da rede hidrográfica e das estradas além da identificação dos padrões de formas do relevo e mudanças na litologia. Em outras campanhas de trabalho em campo, as atividades foram destinadas a estudos de caráter geológico, onde com base no reconhecimento da área e nos mapas base, foram percorridas as estradas analisando os afloramentos distribuídos na área de estudo.

Para descrição, amostragem e obtenção de dados litológicos e de estruturas das rochas, em cada afloramento foram utilizados os materiais de campo como fotografias e anotação de coordenadas obtidas pelo sistema GPS (Global Position System) modelo Garmin Etrex $H$, na projeção cartográfica UTM. Em cada afloramento foram analisadas as seguintes características: o tipo de rocha; as estruturas; os padrões de intemperismo; as zonas potenciais de instabilidade e presença de fluxo de água.

De modo a descrever as rochas adaptou-se a classificação (tabela 2) de Figueiró (1997) para padronizar as rochas de cada afloramento registrado em campo.

$\mathrm{Na}$ quarta etapa do trabalho, pós-campo, seis amostras foram selecionadas para laminação, com o objetivo de apresentar as diferentes texturas das rochas presentes na BHRP sob aspecto microscópico. 0 critério para escolha das amostras para laminação levou em consideração a localização geográfica (pontos distribuídos uniformemente na bacia) e as principais unidades de rocha presentes na área. 
Tabela 1 - Nomenclatura para classificação de rochas aplicada a geotecnia. (Adaptado de FIGUEIRÓ, 1997).

\begin{tabular}{cc}
\hline ID & $\begin{array}{c}\text { TIPO DE ROCHA } \\
\text { R1s }\end{array}$ \\
R1v & $\begin{array}{c}\text { Rocha resistente pouco fraturada } \\
\text { (Sedimentar) } \\
\text { Rocha resistente pouco fraturada } \\
\text { (Vulcânica) }\end{array}$ \\
R2 & $\begin{array}{c}\text { Rocha resistente muito fraturada } \\
\text { R3 }\end{array}$ \\
R4 & Rocha hidrotermalizada amigdalóide \\
R5 & Brecha vulcânica \\
R6 & Vitrófiro \\
R7 & Rocha fraca muito alterada \\
\hline
\end{tabular}

No processo de laminação as rochas foram cortadas em tabletes de aproximadamente $5 \times 3 \times 1 \mathrm{~cm}$, e foram coladas em lâmina de vidro com resina epóxi. Seguindo o procedimento, a amostra foi cortada e desbastada até que a espessura da rocha fosse à desejada (cerca de 30 micrometros). 0 polimento com pasta de diamante foi realizado na sequência. No final do procedimento, realizado no Laboratório de Laminação do Instituto de Geociências da Universidade Federal do Rio Grande do Sul - UFRGS obteve-se uma lâmina delgada onde é possível descrever e identificar os minerais presentes além do arranjo petrográfico em cada rocha analisada.

As análises petrográficas foram realizadas buscando identificar os minerais e as texturas, bem como diferenciar a susceptibilidade das rochas ao intemperismo, pois os processos de dissecação, em qualquer clima, são influenciados pela composição química e/ou mineralógica do substrato geológico.

Na sexta etapa foi analisada a vulnerabilidade das rochas com base no quadro 1 proposta por Crepani (2001). As litologias recebem valores de 1 (estável) a 3 (instável). Estes pesos foram adaptados à realidade dos pontos visitados em campo.

Quadro 1 - Escala de vulnerabilidade à denudação das rochas mais comuns. (CREPANNI, 2001).

\begin{tabular}{||c|c|c|c|c|c|}
\hline \multicolumn{6}{|c|}{ Escala de vulnerabilidade à denudação das rochas mais comuns } \\
\hline $\begin{array}{c}\text { Quartzitos ou } \\
\text { metaquartzitos }\end{array}$ & 1,0 & $\begin{array}{c}\text { Milonitos, Quartzo } \\
\text { muscovita, Biotita, } \\
\text { Clorita xisto }\end{array}$ & 1,7 & $\begin{array}{c}\text { Arenitos quartzosos ou } \\
\text { ortoquartzitos }\end{array}$ & 2,4 \\
\hline $\begin{array}{c}\text { Riólito, Granito, } \\
\text { Dacito }\end{array}$ & 1,1 & $\begin{array}{c}\text { Piroxenito, } \\
\text { Anfibolito } \\
\text { Kimberlito, Dunito }\end{array}$ & 1,8 & $\begin{array}{c}\text { Conglomerados, } \\
\text { Subgrauvacas }\end{array}$ & 2,5 \\
\hline $\begin{array}{c}\text { Granodiorito, } \\
\text { Quartzo Diorito, } \\
\text { Granulitos }\end{array}$ & 1,2 & $\begin{array}{c}\text { Hornblenda, } \\
\text { Tremolita, Actinolita } \\
\text { xisto }\end{array}$ & 1,9 & Grauvacas, Arcózios & 2,6 \\
\hline $\begin{array}{c}\text { Migmatitos, Gnaisses } \\
\text { Fonólito, Nefelina } \\
\text { Sienito, Traquito, } \\
\text { Sienito }\end{array}$ & 1,3 & $\begin{array}{c}\text { Estaurolita xisto, } \\
\text { Xistos granatíferos }\end{array}$ & 2,0 & Siltitos, Argilitos & 2,7 \\
\hline $\begin{array}{c}\text { Andesito, Diorito, } \\
\text { Basalto }\end{array}$ & 1,5 & Ardito, Metassiltito & 2,1 & Folhelhos & 2,8 \\
\hline $\begin{array}{c}\text { Anortosito, Gabro, } \\
\text { Peridotito }\end{array}$ & 1,6 & Mármores & 2,3 & $\begin{array}{c}\text { Inconsolitito } \\
\text { Aluviões, Colúvios etc. }\end{array}$ & 3,0 \\
\hline
\end{tabular}

\section{Resultados e discussão}

A Bacia Hidrográfica do Rio Paranhana apresenta no setor centro-norte um relevo caracteristicamente escarpado constituído por vertentes escalonadas em patamares (Figura 2) modelados pela alternância de derrames basálticos e riolíticos

A análise e interpretação dos dados de geologia e geomorfologia identificaram as zonas de contato entre os diferentes derrames e entre as formações Botucatu e Serra Geral. Essas zonas são susceptíveis a desastres naturais. A fragilidade é potencializada, nestas regiões, devido ao relevo e à urbanização nos municípios de Três Coroas e Igrejinha.

No caráter geológico cabe ressaltar que as estru- turas de fluxo magmático são, sem dúvida, o fator mais importante na determinação da qualidade da rocha, pois elas originam uma permeabilidade adicional à rocha, facilitando a percolação de água, o que acelera os processos intempéricos gerando materiais de baixa resistência. (NUMMER, 2003).

Na BHRP a intensidade da alteração intempérica do maciço rochoso está diretamente relacionada à presença de estruturas de resfriamento e tectônicas. A imagem de relevo sombreado, por ser uma das maneiras mais realistas de se representar dados tridimensionais em um ambiente bidimensional, foi utilizada para extrair os lineamentos estruturais apresentados no (Figura 3). 
Figura. 2 - Relevo escalonado em patamares. Município de Igrejinha/RS.

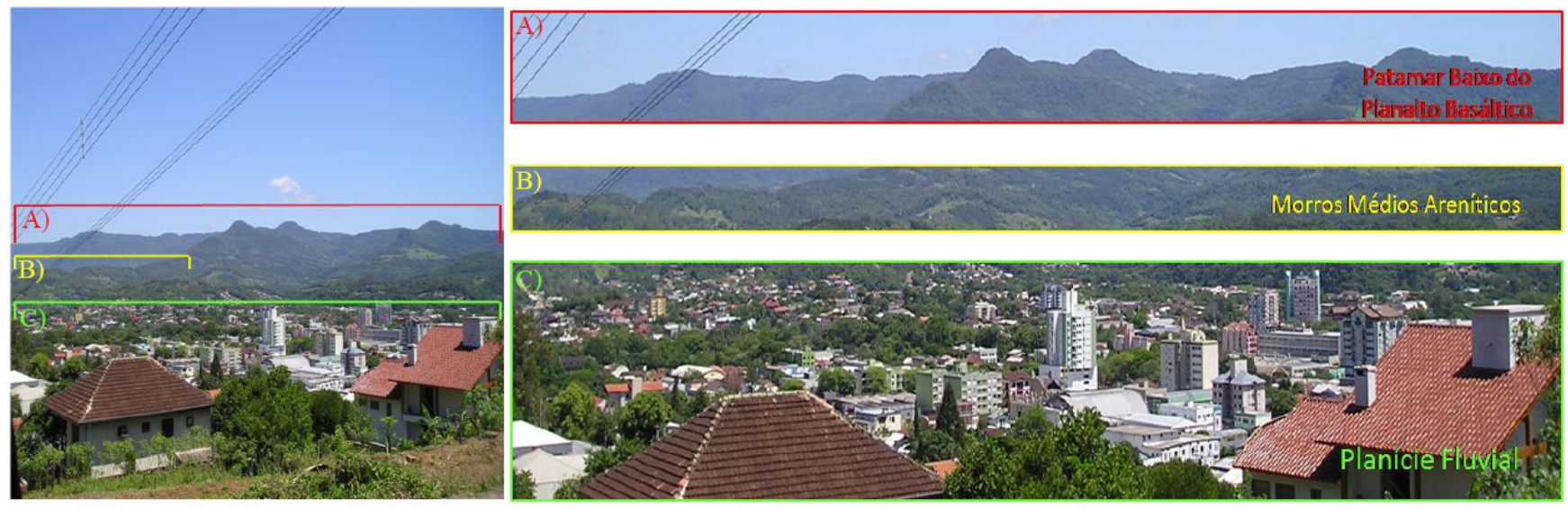

Figura 7. Visada de três compartimentos (A, B e C) do segundo táxon. Igrejinha - RS. Fonte: Autora (2012).

Figura 3 - Espacialização dos lineamentos estruturais da bacia hidrográfica do Rio Paranhana.

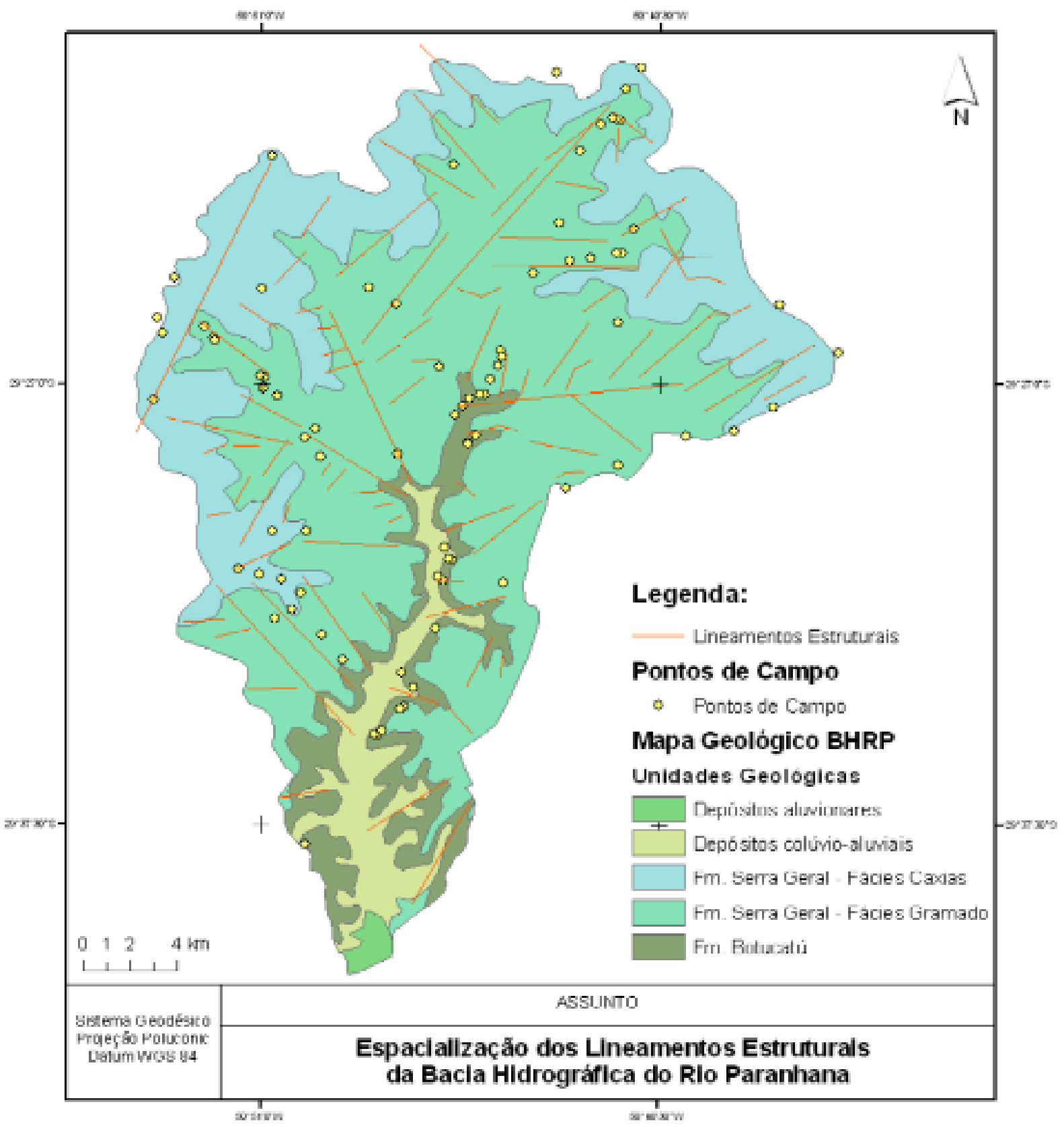


Os lineamentos sugerem a direção ou caminhos preferenciais de percolação da água de infiltração no maciço rochoso. Deste modo, quanto maior a densidade de estruturas, conforme observado nas porções rochosas com estrutura de fluxo, maior a intensidade dos processos intempéricos.

De acordo com as análises geológicas, percebe-se que as zonas suscetíveis da bacia não se limitam somente aos contatos entre as formações Botucatu e Serra Geral, mas também aos contatos entre derrames da Fm. Serra Geral. Estes últimos não foram mapeados em função do tempo para o mapeamento, mas os pontos identificados em campo situam-se em zonas de contato entre derrames e entre diferentes litologias.

A espacialização gerada a partir dos dados de campo (pontos descritos), referencial bibliográfico e índice de vulnerabilidade das rochas de Crepanni (2001), de- monstra que segundo a geologia as zonas suscetíveis abrangem praticamente toda a área aflorante da Fm. Botucatu e da Fm. Serra Geral (Fácies Gramado). Isto se deve as áreas de contato litológico e a faciológia geológica existente como já citado que possuem estruturas que permitem a infiltração de fluídos e a consequente alteração dos minerais das rochas.

Este relevo se apresenta escalonado devido ao afloramento de rochas básicas/ intermediárias (Fácies Gramado), ácidas (Fácies Caxias) e rochas sedimentares (Formação Botucatu) que geram zonas de percolação nos contatos. Com base nas variáveis de declividade e curvatura vertical (Figuras 4 a e 4 b) foi possível identificar zonas bem definidas de relevo escarpado. Estas coincidem com a mudança de litologia segundo o mapa geológico.

Figura. 4 - a) Declividade da Bacia do Rio Paranhana; b) Curvatura Vertical da Bacia do Rio Paranhana.

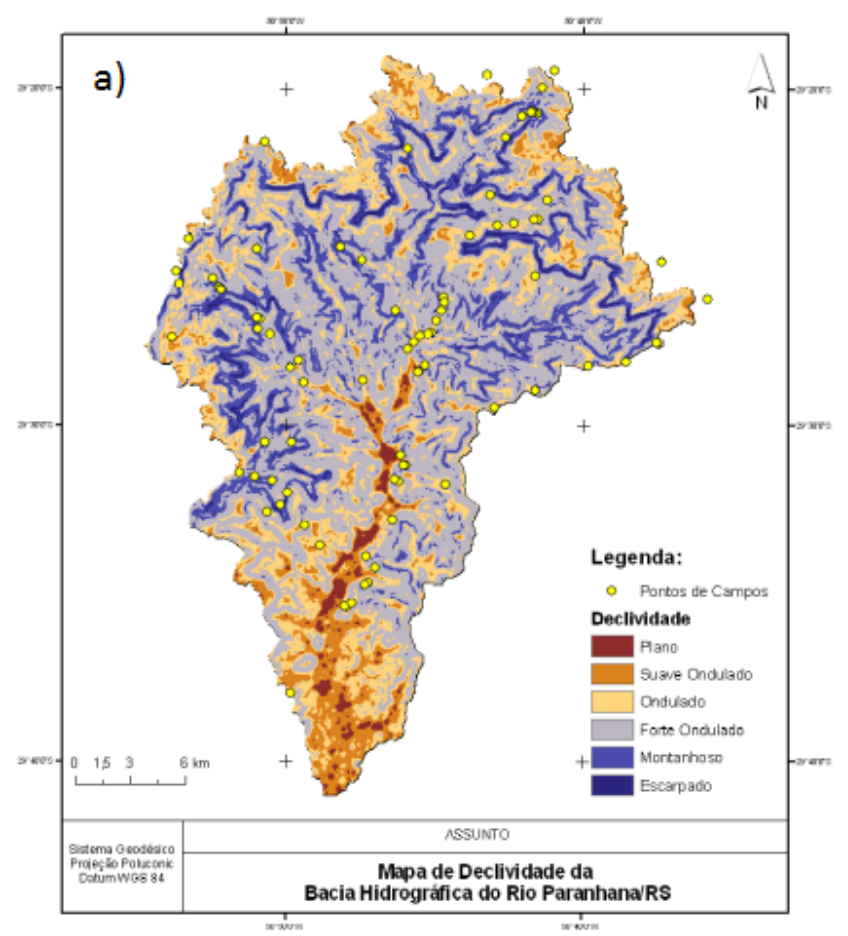

A formação geológica mais antiga (Formação Botucatu) está distribuída uniformemente por toda a bacia atingindo todos os municípios, enquanto as rochas vulcânicas básicas e ácidas são encontradas no rebordo do planalto, nas bordas norte e nordeste da bacia encobrindo os municípios de Canela, Gramado e São Francisco de Paula. A Formação Botucatu vincula-se ao relevo de colinas na zona centro-sul da bacia, região identificada como de maior incidência de desastres naturais.

Geomorfologicamente somaram-se as zonas instáveis, as áreas de vertentes convexas e de altas declividades. As áreas do planalto ao norte da bacia encontram-se classificadas como estáveis, pois a partir do planalto ocorre uma ruptura acentuada do relevo,

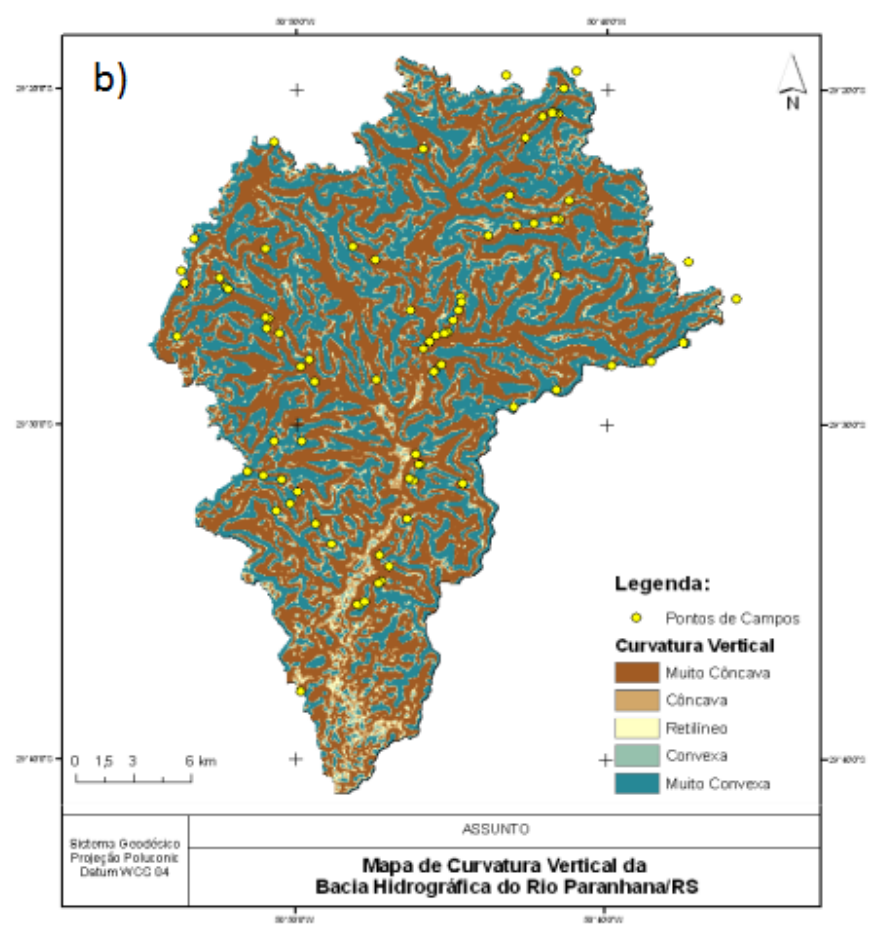

dando origem a um sistema de altas declividades representado pelos paredões rochosos da Fácies Caxias. No centro da bacia apresenta-se um relevo em forma de patamares, escalonado, onde Nummer (2003) nomeia este como sistema de terreno Meia Encosta. Os patamares são compostos pela sucessão de derrames magmáticos da formação Serra Geral, nesta região a declividade se alterna entre acentuada (norte) e moderada (sul).

No sul da bacia junto à área de foz do rio Paranhana, as áreas planas foram classificadas como estáveis, visto que o critério para os pesos de ponderação levou em considerações as variáveis que permitissem as análises das formas de relevo principalmente com base no substrato geológico. 
Os oitenta e quatro pontos visitados em campo encontram-se em área onde a vulnerabilidade é moderada, pois seguem os cortes de estrada, geralmente realizados em vertentes côncavas de média declividade. No nordeste da bacia no município de Gramado foram identificados cicatrizes de deslizamentos em altas declividades e altas altitudes. Confirmando que embora esta região não possua um aporte de sedimento para movimentos de massa, a instabilidade litológica de al- guns pontos torna esta área moderadamente vulnerável.

Os pontos percorridos na estrada da represa $\mathrm{Bu}$ gres do município de Canela (seguindo da cota $748 \mathrm{~m}$ à $91 \mathrm{~m}$ ) até o município de Três Coroas permitiram aferir a influência das estruturas de contato litológico e faciológico na estabilidade das rochas. Validando o produto cartográfico final (Figura 5), onde se atribuiu um peso maior à litologia e à declividade.

Figura 5 - Vulnerabilidade Ambiental da Bacia Hidrográfica do Rio Paranhana.

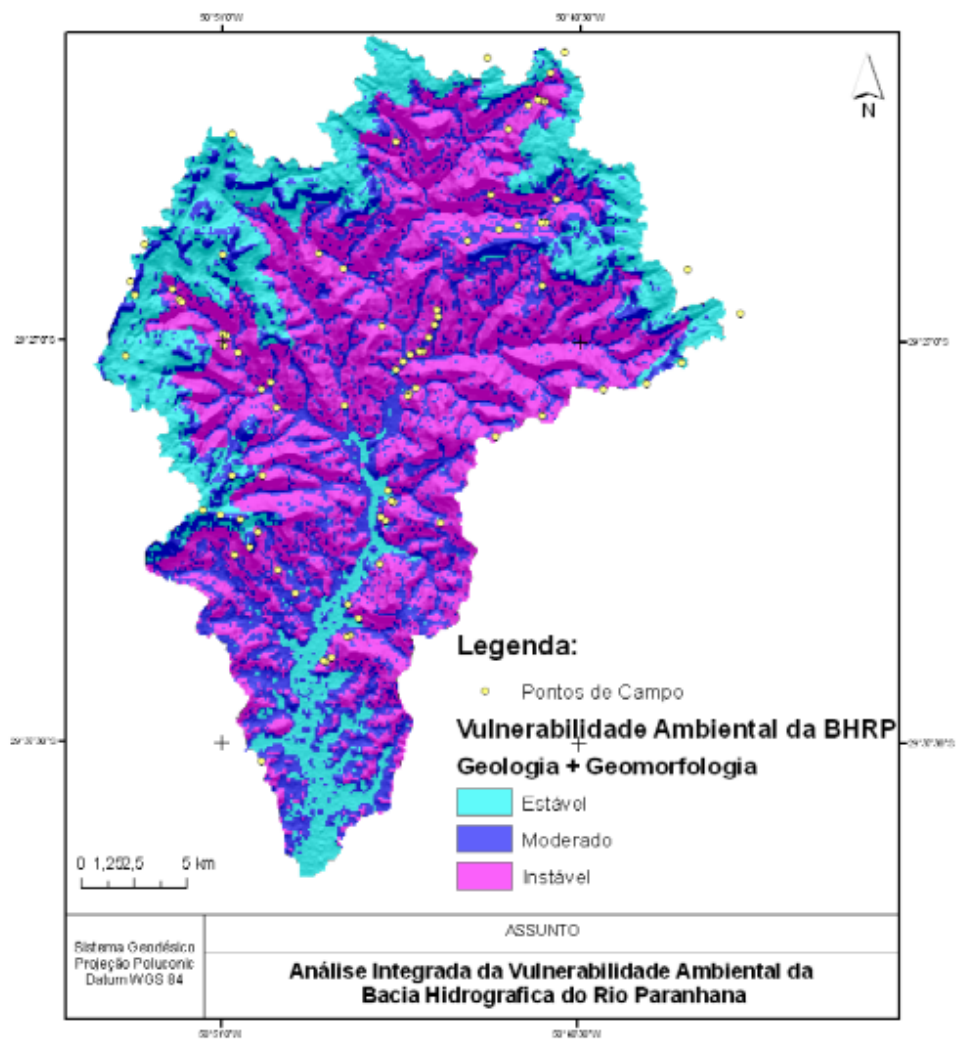

\section{Conclusões}

A bacia hidrográfica do Rio Paranhana situada na encosta do planalto meridional possui relevo escarpado, constituído por vertentes escalonadas em patamares e modelado pela alternância de derrames magmáticos. Os mecanismos de instabilização desses taludes dependem de fatores geológicos, geomorfológicos e estruturais.

Trabalhos desenvolvidos em áreas de escarpa no nordeste do estado do Rio Grande do Sul (NUMMER, 2003; VANACÔR, 2006; RIFFEL, 2012) reconheceram e caracterizaram áreas com fragilidade ambiental, investigando movimentos de massa. 0 presente artigo utilizou estas referências como base, porém a investigação teve um caráter geológico acentuado a partir da hipótese de que as áreas de contato lito-faciológico também demandam atenção no estudo de ambientes vulneráveis.

Os resultados obtidos em campos no processamento dos dados geomorfométricos foram satisfatórios. A metodologia multicritério de álgebra de mapas possibilitou a integração dos dados geológicos com os geomorfológicos, destacando áreas vulneráveis (instável, moderado, e estável) da BHRP.

A interpretação foi possibilitada a partir da classificação dos tipos de rochas proposta por Figueiró (1997), esta classificação tornou possível caracterizar o tipo de rocha pela estrutura aflorante, facilitando a interpretação em relação à vulnerabilidade das rochas. Rochas do Tipo R2 (rocha resistente muito fraturada), R3 (rocha hidrotermalizada amigdalóide), R6 (rocha fraca muito alterada) e R7 (rocha com estrutura de fluxo) indicam área de contato de derrames.

A geomorfologia da BHRP acompanha as mudanças do substrato geológico fazendo com que grande parte da área de estudo não seja apta à ocupação regular (urbana), visto que $80 \%$ da área do centro para o norte da bacia é considerado instável frente às altas declividades e às acentuadas curvaturas verticais. A tendência é de que os municípios se expandam cada vez mais, e que as ocorrências de desastres naturais aumentem. 


\section{Referências}

BASSO. L. A. Bacias Hidrográficas do Rio Grande do Sul: Implicações ambientais. In: VERDUM, R; BASSO, L. A; SUERTEGARAY, D. M. A. Rio Grande do Sul: Paisagens e Territórios em Transformação. Editora da UFRGS. Porto Alegre - RS. 2004. BRUBACHER, J.P. et al. Suscetibilidade de enchentes a partir da análise das variáveis morfométricas na bacia hidrográfica do rio dos Sinos/RS. Anais XV Simpósio Brasileiro de sensoriamento Remoto - SBSR, Curitiba-PR. INPE. 2011. P. 1279.

CREPANI, E.; Medeiros, J. S.; Azevedo L.G.; HERMANDEZ Filho, P.; FLORENZANO, T.G.; DUARTE, V.; Curso de sensoriamento remoto aplicados ao zoneamento ecológico-econômico [CD-ROM]. In: Simpósio Brasileiro de Sensoriamento Remoto, 8 Salvador, 1996. Anais. São Paulo: Image Multimídia. Seção de Comunicações Técnico-Científica. 1996.

IBGE. Folha SH.22-X-C Gravataí: Geomorfologia. Diretoria de Geociências. Rio de Janeiro-RJ. Escala: 1:250.000. Formato Digital. 2003.

FIGUERÓ, J. E. Estudo Geológico-Geofísico na Rota do Sol. Relatório do Mapeamento Geológico. ETEL - Estudos Técnicos de engenharia LTDA. Relatório Interno. 1997. Não publicado.

FUJIMOTO, N. S. V. M. Análise Ambiental Urbana na Área Metropolitana de Porto Alegre - RS: Sub-Bacia Hidrográfica do Arroio Dilúvio. Tese de Doutorado. Universidade de São Paulo. Faculdade de Filosofia e Ciências Humanas. São Paulo - SP. 2001.

LUERCE, T. D. Mapeamento geomorfológico a partir de dados SRTM: bacia hidrográfica do rio dos Sinos, RS. Anais XVI Simpósio Brasileiro de Sensoriamento Remoto - SBSR. Foz do Iguaçu, PR. INPE. 2013.

MILANI, E. J. Evolução tectono-estratigráfica da Bacia do Paraná e seu relacionamento com a geodinâmica fanerozóica do Gondwana sul-ocidental. 1997. 2 v. Tese (Doutorado) Universidade Federal do Rio Grande do Sul, Porto Alegre, 1997

MILANI, E.J. Geodinâmica Fanerozóica do Gondwana sul - ocidental e a Evolução Geológica da Bacia do Paraná. In: HOLZ, M.; ROS, L. F. Geologia do Rio Grande do Sul. Porto Alegre: CIGO / UFRGS Porto Alegre, 2000. 444 p. Il.

NUMMER, A. V. Parâmetros Geológico-Geotécnicos controladores dos Movimentos de Massa na Rota do Sol/RS 486 -
Itati, RS. Tese de Doutorado. Universidade Federal do Rio Grande do Sul. Porto Alegre. 2003.

OLIVEIRA, G. G. Modelos para Previsão, Espacialização e Análise das Áreas Inundáveis na Bacia Hidrográfica do Rio Caí, RS. Dissertação de Mestrado. Universidade Federal do Rio Grande do Sul. Centro Estadual de Pesquisas em Sensoriamento Remoto e Meteorologia - CEPSRM. Porto Alegre - RS. 2010.

PENTEADO, F. A. Mapeamento e Análise Geomorfológicos como Subsídio para Identificação e Caracterização de Terras Inundáveis. Estudo de Caso da Bacia Hidrográfica do rio dos Sinos - RS. Tese de doutorado. Universidade de São Paulo. FFLCH - USP. 2011.

PROSINOS. Caracterização Socioambiental da região da Bacia Hidrográfica do Rio dos Sinos. Disponível em:< http:// www.portalprosinos.com.br/conteudo.php?id=bacia>. Acessado em 14 de Agosto de 2013.

PROSINOS. Caracterização Socioambiental da região da Bacia Hidrográfica do Rio dos Sinos. Disponível em:<http:// www.portalprosinos.com.br/conteudo.php?id=bacia>. Acessado em 14 de Agosto de 2013.

RIFFEL, E. S. Análise e mapeamento das ocorrências de movimentos de massa na bacia hidrográfica do Rio Paranhana (RS). Dissertação de mestrado. Universidade Federal do Rio Grande do Sul. Instituto de Geociências. Porto Alegre - RS. 2012.

ROISENBERG, A.; VIERO, A.P.o. Vulcanismo Mesozóico da Bacia do Paraná no Rio Grande do Sul. In: HOLZ, M.; ROS, L. F. Geologia do Rio Grande do Sul. Porto Alegre: CIGO / UFRGS Porto Alegre, 2000. 444 p. Il.

ROSS, J. L. S. Análise empírica da fragilidade de ambientes naturais antropizados. In: Revista do Departamento de Geografia. São Paulo - SP. FFLCH - USP. no 8. 1994.

SCHERER, C.M.S. et al. Arcabouço Estratigráfico do Mesozóico da Bacia do Paraná. In: HOLZ, M.; ROS, L. F. Geologia do Rio Grande do Sul. Porto Alegre: CIGO / UFRGS Porto Alegre, 2000. 444 p. Il

VANACÔR, R. N. Sensoriamento remoto e geoprocessamento aplicados ao mapeamento das áreas susceptíveis a movimentos de massa na região nordeste do estado do Rio Grande do Sul. Dissertação de mestrado. Centro de Pesquisas em Sensoriamento Remoto e Meteorologia. UFRGS. 2006.

\begin{abstract}
The geological and geomorphological recognition process has routinely fundamental the division of the area in units, according to the change of its character. The units represent areas with minimal heterogeneity as attributes and, compartments with similar responses compared to the dynamic processes of surface. By submitting a relief steep, slope of the plateau regions, are scenes of frequent natural disasters (mass movements and floods). Any change in the components of nature (topography, soil, vegetation, climate and water resources) entails the commitment of system functionality, thereby breaking with the dynamic equilibrium of this. In the river basin Paranhana situated on the right bank of the Rio dos Sinos, the slope of the geomorphological unit of the Southern Plateau, floods and mass movements are due to the characteristically steep relief. Studies conducted in the study area have identified with Civil Defense that between the years 2003 to 2012 there were thirty-seven occurrences of natural disasters characterized as windstorm, tornado, flood, mass movements and hail. In this context, the important geological and geomorphological studies, which will assist in planning and mapping of areas with environmental fragility. The interpolation of geological and geomorphological date added to the field data rate possible areas of greatest susceptibility. These zones are recorded mainly in the municipalities of the Três Coroas and Igrejinha, where the substrate is characterized by sandstones of Botucatu and lithological contact zones with basalts of the Serra Geral.
\end{abstract}

Keywords: River Basin Paranhana; Geology, Geomorphology, Environmental Susceptibility. 